\title{
Design of Solar Tracker System Using Phototransistor
}

\author{
Ahmad Fauzan 'Adziimaa ${ }^{1 *}$, Detak Yan Pratama², Nabila Widad Dira Sinatrya1, Dewi Sugihartati \\ Wahyu Nur Handayani ${ }^{1}$
}

\begin{abstract}
Intensity of the sun be an important parameter to determine the potential energy in any region. Nowdays, measurement of solar intensity as a panel solar tracker use many variety of sensors. Phototransistor is one of the light sensors that has a greater light sensitivity compared to other light sensors. The design of the system uses four phototransistor which are placed each of two sensors in the east and west of the panel. Accuracy testing calculated by comparing the measurement results on sensor circuit with Lux Meter as validator. The results have shown that the average of phototransistor error is $1.24 \%$ and $1.27 \%$ on the east side phototransistor and $0.47 \%$ and $0.93 \%$ on the west side phototransistor.
\end{abstract}

\section{Keywords-- Phototransistor, Solar tracker}

\section{INTRODUCTION}

Solar Tracking system is a method used to harvesting sunlight based on the direction of the sun's motion to get maximum power, because the possibility of maximum sun intensity is obtained when the surface is perpendicular to the sun. To follow the direction of the sun, it needed a light sensor as a reading of light intensity. There are variety types of light sensors including LDR (Light Dependent Resistor), phototransistor, photodiode, etc.

In previous research, a similar design has been carried out, except that the solar tracking system has not been able to work optimally because the previous Solar Tracker used an LDR sensor which has an average response time of $10 \mathrm{~ms}$ to changes in light intensity. In addition, the LDR sensor from the panel is placed on the center edge of the panel which results in poor sensor reading accuracy. This affects the reading of sunlight intensity so that the DC $\mathrm{H}$-Bridge motor driver who acts as a regulator of the motor rotation does not run properly [1].

In this work, phototransistor used to build a solar tracking system to replace LDR. Phototransistor has an internal amplifier to magnify the current that comes out from the sensor up to hundreds of times, so the sensitivity in reading the light intensity is better than the LDR $[2,4]$. Photodiode able to increase the sensitivity of the sensor to slight changes in light, four sensors were installed in two parts, two sensors in the eastern part of the framework and two sensors in the western part of the framework.

\section{METHOD}

\section{A. Design of Detection System}

System of solar tracker use four phototransistors that set up at the edge of framework. This is the block diagram of solar detection system.

${ }^{1}$ Departement of Instrumentation Engineering, Institut Teknologi Sepuluh Nopember, Kampus ITS Sukolilo, Surabaya, 60111, Indonesia. Email: ahmadfauzan.epits@gmail.com

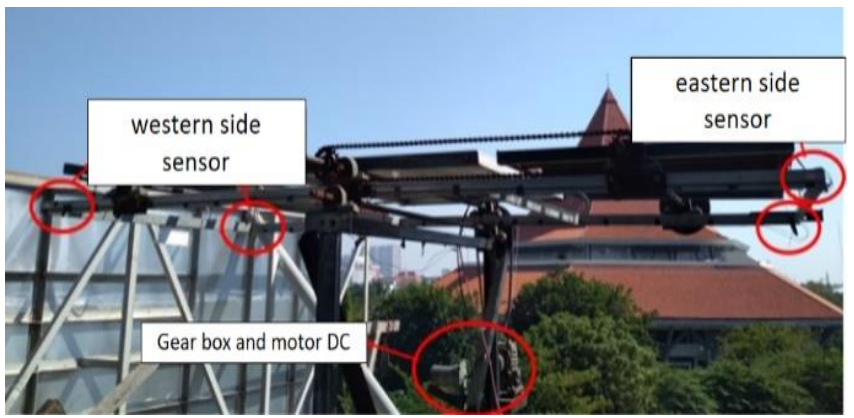

Figure 1. Components in the main framework

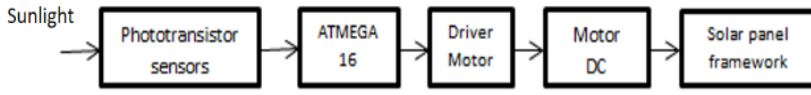

Figure 2. Block diagram of directional light detection system using phototransistor [3]

The main framework has one degree of freedom where located from eastern to western that shown in Figure 3. Motor rotation is controlled by a microcontroller that is programmed according to the position of direction the sun's light. The motion of framework will get a certain angle.

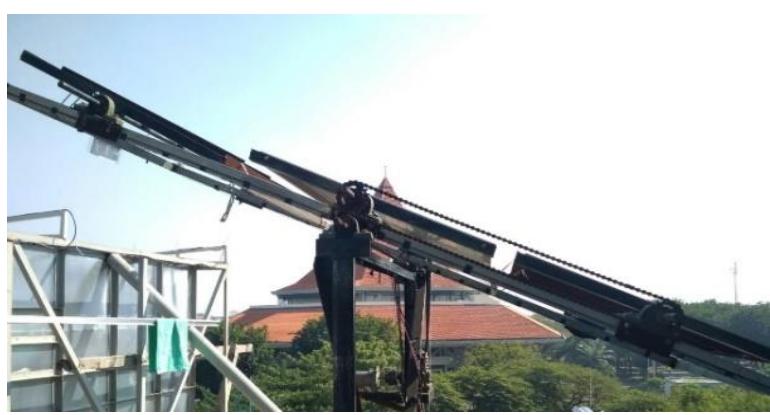

Figure 3. Main framework single axis

${ }^{2}$ Departement of Instrumentation Engineering, Institut Teknologi Sepuluh Nopember, Kampus ITS Sukolilo, Surabaya, 60111, Indonesia. 
Microcontroller will move the main framework based on the output signal of phototransistor. The working system of solar detection system is given in the Figure 4.

\section{B. Design of Phototransistor as Sensor}

Intensity of sunlight falling to the base of phototransistor will affect the magnitude of impedance. Greater intensity will show small impedance, and cause bigger current from collector to emitter. Table 1 is the impedance of the phototransistor in the dark and bright conditions.

TABLE 1. IMPEDANCE PHOTOTRANSISTOR SENSOR

\begin{tabular}{lcc}
\hline \hline Illumination (lux) & Voltage (volt) & $\begin{array}{c}\text { Impedance } \\
\text { sensor }(\boldsymbol{\Omega})\end{array}$ \\
\hline 14080 & 5,07 & $12000 \Omega$ \\
4710 & 1,5 & $165,7 \Omega$ \\
\hline \hline
\end{tabular}

Impedance in table 1 are used to calculate the number of resistor that used in the voltage divider circuit and can be calculated from the equation below

$$
\mathrm{V}_{\text {out }}=\frac{R 1}{\text { Rsensor }+R 1} x \text { Vin }
$$

Phototransistor was integrated with a voltage divider circuit to determine the voltage that can be read by a microcontroller.

\section{Design of Microcontroller}

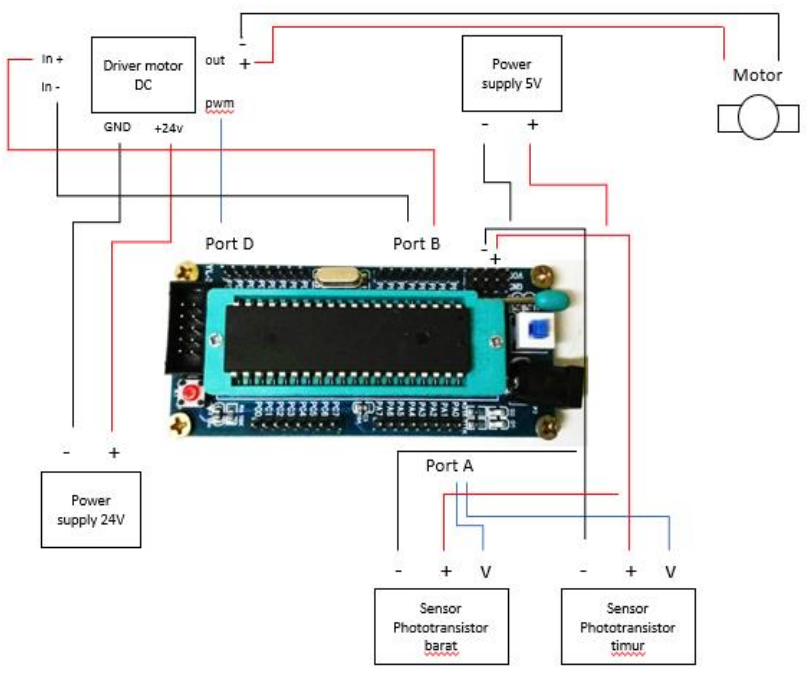

Figure 4. Wiring ATMEGA16

Sensor using a 5 VDC supply. PORT A is specialized as PORT ADC (Analog to Digital Converter), PORT B is used as input for motor drivers, while PORT D is used as a port for $16 x 2$ LCD Display.

\section{Design $H$-Bridge Driver Motor}

DC motor is used to drive the main frame of the solar panel. The 19 DC motor is used in this work. This system also uses a gear box with a ratio of 1:60. The gear box is one of the main components of the motor which is referred to as a power transfer system, which is changing the power of a rotating motor. DC H-Bridge Motor Driver circuit consisting of mosfets with type IRF9540 and IRF530 with the logic given to the Opto-coupler $4 \mathrm{n} 25$ as a safety if there is a reverse induction and also serves to facilitate in determining the direction of rotation of DC motor.

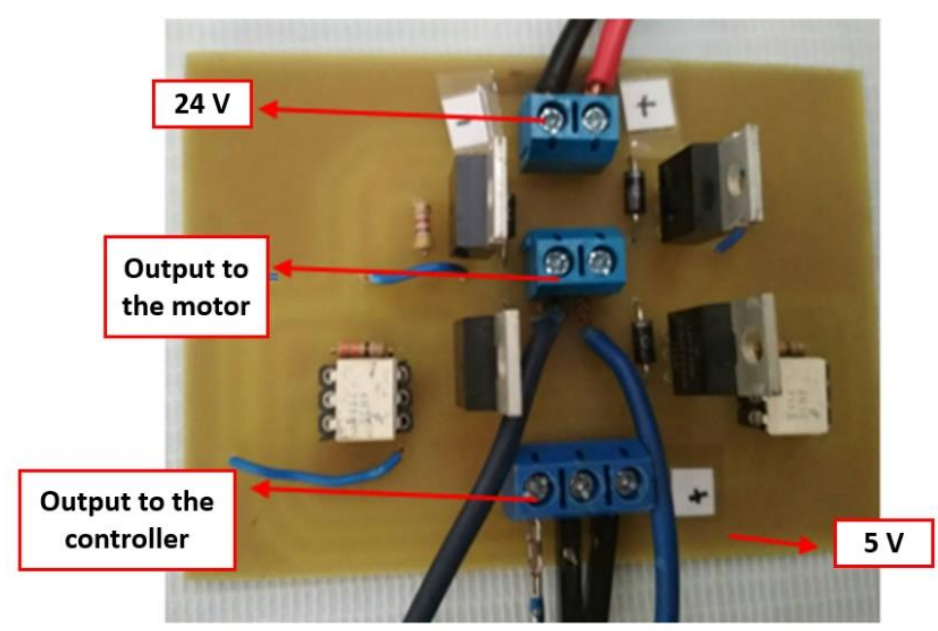

Figure 5. Driver of Motor DC

E. Program of detection system

Making a program for this detection system using Software Programmer's Notepad. The program display is shown in Figure 7.

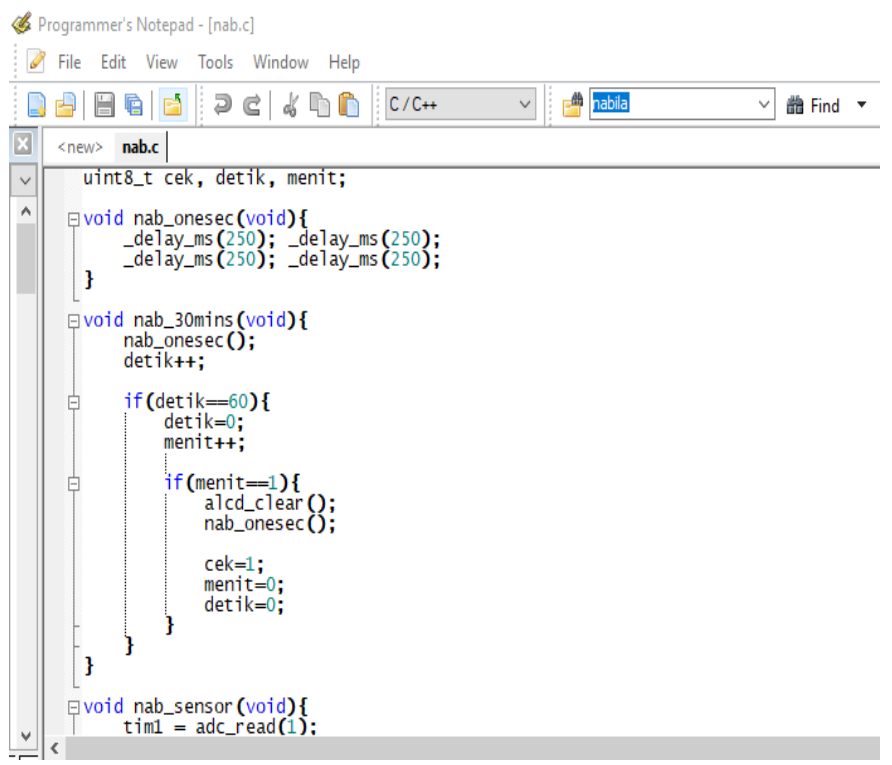

Figure 6. Program of detection system

The program flow of this detection system is to compare the average of eastern sensor with the average of western sensor. If the west sensor is greater than the east, the microcontroller will command the motor to move facing the western with a determined difference. 


\section{RESULTS AND DISCUSSION}

\section{A. Sensor Phototransistor testing}

This sensor test to find out the sensor is compatible with this solar tracker system, to comparing the standard device with a lux meter. Put the phototransistor sensor beside the Lux meter then it is moved by moving the satellite dish with the five angle points of the sensor's tilt from the upright direction of the sun. The sensor angle can be known from equation (2).

$$
\operatorname{Tan} \emptyset=\frac{y}{x}
$$

$\mathrm{y}$ is the length of the sensor and $\mathrm{x}$ is the length of the sensor shadow. The phototransistor sensor to be perpendicular to the sun when the shadow length is 0 or there is no shadow. The results of the test can be seen in the graphs in Figure 7 and Figure 8 . That each vertex changes the greater the angle of the sensor's tilt, the greater the intensity of sunlight obtained.

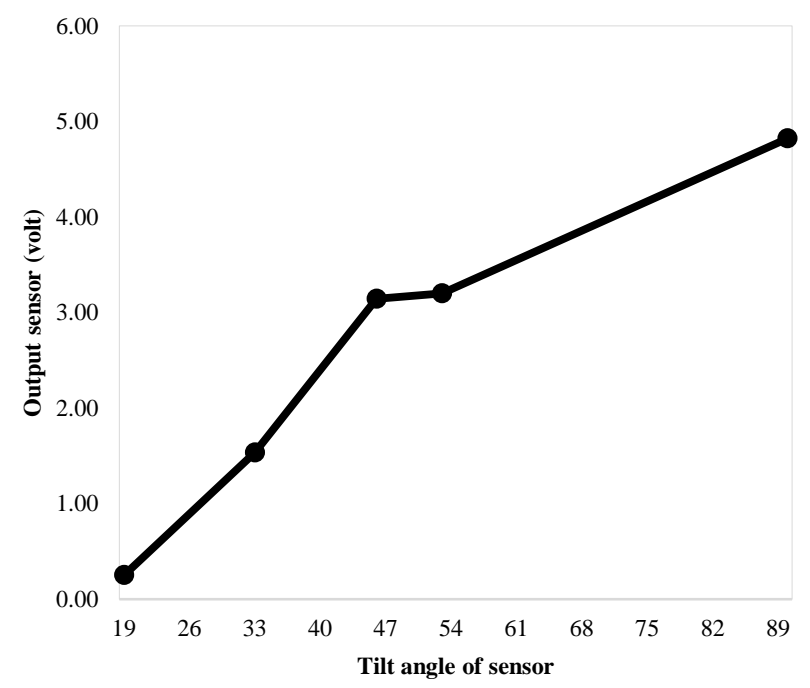

Figure 7. Graph of the relation between the sensor readings with the sensor tilt angle

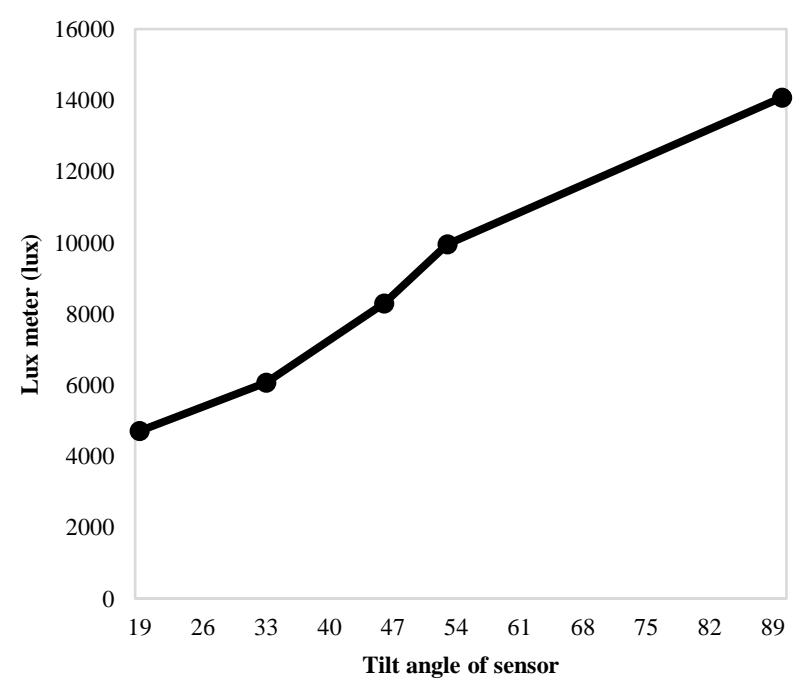

Figure 8. Graph of the relation between the Lux meter reading and the sensor tilt angle
Validation of the phototransistor sensor is compared with the lux meter which is carried out from 08.00 to 17.00 , so that the ADC value on the east sensor in table 2 is obtained before calibration.

TABLE 2.

LIGHT INTENSITY DATA AND ADC VALUE OF EASTERN PHOTOTRANSISTOR SENSOR

\begin{tabular}{|c|c|c|c|c|}
\hline \multirow{2}{*}{ Time } & \multicolumn{2}{|c|}{$\begin{array}{l}\text { Result of ADC } \\
\text { sensor }\end{array}$} & \multicolumn{2}{|c|}{$\begin{array}{l}\text { Result of Lux meter intensity } \\
\text { (cd) }\end{array}$} \\
\hline & $\begin{array}{l}\text { East } \\
1\end{array}$ & $\begin{array}{l}\text { East } \\
2\end{array}$ & East 1 & East 2 \\
\hline 08.00 & 132 & 48 & 18811,26 & 16847,80 \\
\hline 08.30 & 147 & 56 & 24650,99 & 18589,58 \\
\hline 09.00 & 184 & 76 & 29388,64 & 19191,29 \\
\hline 09.30 & 192 & 121 & 80122,04 & 20489,71 \\
\hline 10.00 & 195 & 156 & 191596,18 & 196029,81 \\
\hline 10.30 & 199 & 188 & 199830,06 & 186529,17 \\
\hline 11.00 & 206 & 192 & 207747,26 & 195713,12 \\
\hline 11.30 & 216 & 231 & 210280,76 & 196029,81 \\
\hline 12.00 & 227 & 240 & 214397,71 & 202363,57 \\
\hline 12.30 & 231 & 248 & 216297,83 & 191912,87 \\
\hline 13.00 & 243 & 252 & 220098,09 & 212814,27 \\
\hline 13.30 & 227 & 207 & 205213,76 & 191912,87 \\
\hline 14.00 & 216 & 199 & 207430,57 & 180512,10 \\
\hline 14.30 & 207 & 192 & 184629,04 & 157710,57 \\
\hline 15.00 & 176 & 167 & 167527,90 & 141242,80 \\
\hline 15.30 & 152 & 143 & 149160,00 & 126358,47 \\
\hline 16.00 & 143 & 79 & 80122,04 & 85505,73 \\
\hline 16.30 & 131 & 56 & 49276,64 & 43291,24 \\
\hline 17.00 & 101 & 43 & 45286,37 & 39871,01 \\
\hline
\end{tabular}

From table 2, linear equation $\mathrm{y}=\mathrm{mx}+\mathrm{b}$ is obtained $\mathrm{y}=$ $1612.7 \mathrm{x}-157004$ and $\mathrm{y}=969.63 \mathrm{x}-20168$ which will be used for the phototransistor sensor calibration equation, so the test data in table 2 obtained an average error east 1 is $1.24 \%$ and average error east 2 is $1.27 \%$.

\section{B. Static Characteristic}

Static characteristic is a characteristic that needs to be considered when the tool is used to measure a condition [5]. To find out the characteristics of the calculation below:

$$
\begin{aligned}
& \text { Sensitivity }=\frac{\Delta O}{\Delta I} \\
& \text { Accuracy }==1-\left|\frac{\mathrm{Yn}-\mathrm{Xn}}{\mathrm{Yn}}\right| \times 100 \% \\
& \text { Error }=1-A(\text { accuracy }) \\
& \text { Nonlinearities }=\frac{[\mathrm{O}-(\mathrm{K} I+a)] \mathrm{max}}{\text { Omax }- \text { Omin }} \times 100 \%
\end{aligned}
$$

So the static characteristic values of the Phototransistor Sensor include: 
TABLE 3.

STATIC CHARACTERISTIC OF EAST PHOTOTRANSISTOR SENSOR

\begin{tabular}{lc} 
& SENSOR \\
\hline \hline Range & $56540,93-170583,93 \mathrm{~cd}$ \\
Span & $114,043 \mathrm{~cd}$ \\
Sensitivity & 0,5742 \\
Accuracy & $92,55 \%$ \\
Error & $7,45 \%$ \\
Non Linearitas & $0,007 \%$ \\
\hline \multicolumn{2}{c}{} \\
STATIC CHARACTERISTIC OF WEST PHOTOTRANSISTOR \\
\multicolumn{2}{c}{ TABLNOR } \\
\hline \hline Range & $17659-206156,25 \mathrm{~cd}$ \\
Span & $188497,26 \mathrm{~cd}$ \\
Sensitivity & 1,3527 \\
Accuracy & $99,53 \%$ \\
Error & $0,47 \%$ \\
Non Linearitas & $4,7 \%$ \\
\hline \hline
\end{tabular}

From the Table 3, it can be seen that the sensor accuracy for the western panel is better than the east panel. This condition due to some disturbance in the form of shadows of objects when sunlight hits from the east. Whereas in the west, there is no shadow obstruction so the sensor can read properly. The accuracy of the phototransistor sensor reaches 90\% which is better than the LDR sensor in previous studies.

\section{DC Motor Testing}

For testing the current and voltage using a Multimeter and stopwatch, this is to determine the current and voltage through the driver to the DC motor do not exceed the specifications of the mosfet used, namely IRF9540 and IRF530 with a maximum voltage of $25 \mathrm{~V}$. below this current and voltage data on the motor DC every motion of framework

TABLE 5.

DATA OF CURRENT AND VOLTAGE MOTOR DC

\begin{tabular}{cccc}
\hline \hline Time & second & voltage (volt) & $\begin{array}{c}\text { Current } \\
\text { (Ampere) }\end{array}$ \\
\hline \multirow{2}{*}{$\mathbf{0 8 . 0 0}$} & 1 & 11,9 & 2,48 \\
& 2 & 12,3 & 2,56 \\
& 3 & 12,9 & 2,69 \\
& 4 & 13,1 & 2,73 \\
\multirow{13.00}{*}{} & 1 & 12,3 & 2,56 \\
& 2 & 13,3 & 2,80 \\
& 3 & 12,9 & 2,69 \\
& 4 & 12,7 & 2,64 \\
$\mathbf{1 7 . 0 0}$ & 1 & 11,3 & 2,35 \\
& 2 & 11,5 & 2,34 \\
& 3 & 12,3 & 2,56 \\
\hline \hline
\end{tabular}

\section{Discussion}

This directional light detection system is an integration of several instruments used, namely Phototransistor Sensors, DC Motors, and solar panel frameworks whose purpose that the motor can move the solar panel's framework to facing the direction of sunlight. Phototransistor sensor set in 4 points, 2 points in the west and 2 points in the east. Control of the Solar Tracker is based on the difference from the average eastern sensor and the average western sensor which will then move the DC motor for 4 seconds to expose the framework to the sun until it is perpendicular to the sun.

In each section 2 sensors are installed, purpose of when capturing sunlight to be more accurate. Because it could be that one sensor is blocked by shadows, so the reading of one of the sensors is less than optimal. As in the 23rd corner at 15:30 the reading of western sensor has decreased due to a shadow blocking one of the western sensors, so that the average of the western sensor reading is small, whereas in theory the western sensor at 15.30 gets more intensity of sunlight. Result of the change in frame angle is also not the same because the motor movement is sometimes slow in turning due to the influence of the gearbox, the motor rotation can move the frame every time 2-3 times in an interval of 4 seconds. This is a graph of the change in angle on the solar panel framework for each 30-minute change.

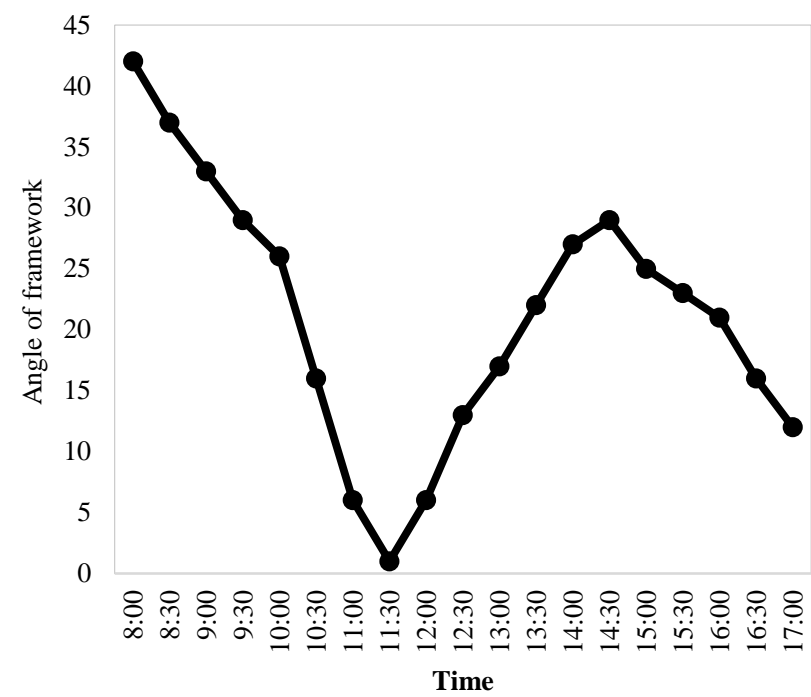

Figure 9. The relation of changes in the main frame angle to time

\section{CONCLUSION}

Static characteristics obtained on the eastern phototransistor sensor sensitivity, value of sensors is 0.5742 , accuracy of $92.55 \%$, error of $7.45 \%$, and nonlinearity of $0.007 \%$. While the western phototransistor sensitivity, value of sensors is 1.3527 , accuracy is $99.53 \%$, error is $0.47 \%$, and nonlinearity is $4.7 \%$.

From the reading of the phototransistor sensor the difference is obtained between the average of eastern phototransistor sensor and western phototransistor sensor. From this difference, motor can move the main frame work by changing the angle. 


\section{REFERENCES}

[1] D. M. Kristina, "Comparison of Several Sensors as Arduino Uno-Based Illumination Gauges," http://repositori.usu.ac.id, 2017.

[2] K. Krismono, "Design and control of dual-axis vertical array designed dc motor stepper," https://repository.its.ac.id, 2018.

[3] L. Wenden, "Sun tracking automatically for electric generators", Mechanical Eng. Journal vol. 3, pp. 1-6, Sept.1991.

[4] H. Andrianto, "Microcontroller programming avr atmega16," Jurnal Teknologi Rekayasa, vol. 1307, no. 2013, p. 8535, 2015.

[5] S. Roni, "Design of solar tracker based on atmega8535 microcontroller with ldr sensor and lcd viewer," J. Fis. Unand, vol. 4, no. 2, pp. 113-122, 2015. 